Article

\title{
An Effective Approach to Improve the Photocatalytic Activity of Graphitic Carbon Nitride via Hydroxyl Surface Modification
}

\author{
Zizhen Li, Xiangchao Meng $\mathbb{D}^{\mathbb{D}}$ and Zisheng Zhang * \\ Department of Chemical and Biological Engineering, University of Ottawa, Ottawa, ON K1N 6N5, Canada; \\ zli125@uottawa.ca (Z.L.); xmeng086@uottawa.ca (X.M.) \\ * Correspondence: zzhang@uottawa.ca; Tel.: +1-613-562-5800 (ext. 6110)
}

Received: 25 November 2018; Accepted: 24 December 2018; Published: 28 December 2018

\begin{abstract}
In this work, we have developed a hydrothermal method to modify g- $\mathrm{C}_{3} \mathrm{~N}_{4}$ with hydroxyl surface modification. Modified g- $\mathrm{C}_{3} \mathrm{~N}_{4}$ has exhibited higher photocatalytic activity in the removal of phenolic compounds under visible light. The improvement may be due to the following merits: (1) Tuning of the hydrophobic surface of $\mathrm{g}-\mathrm{C}_{3} \mathrm{~N}_{4}$ to be hydrophilic; (2) improved adsorption energy, and (3) narrowed band gap for $\mathrm{g}-\mathrm{C}_{3} \mathrm{~N}_{4}$ after hydroxyl surface modification. This method is easy-to-operate, very effective in adding hydroxyl groups on the surface of $\mathrm{C}_{3} \mathrm{~N}_{4}$, and may be extended to other systems to promote their photocatalytic activities in water treatment.
\end{abstract}

Keywords: water treatment; photocatalysis; g- $\mathrm{C}_{3} \mathrm{~N}_{4}$; hydroxyl; surface modification

\section{Introduction}

Graphitic carbon nitride $\left(\mathrm{g}-\mathrm{C}_{3} \mathrm{~N}_{4}\right)$, as a fascinating conjugated polymer, has become a hot research topic [1]. As a metal-free photocatalytic semiconductor, $\mathrm{g}-\mathrm{C}_{3} \mathrm{~N}_{4}$ is very promising in energy storage and environmental remediation [2]. When $\mathrm{g}-\mathrm{C}_{3} \mathrm{~N}_{4}$ is implemented in photocatalytic water treatment, one of the hindrances is the hydrophobic properties of the surface. Photocatalysis is a process that occurs at the interface between the liquid and the solid phase, therefore, the adsorption of water as well as of the target pollutants is the first step and very significant. Surface modification may be an effective approach to improve the adsorption of water onto the surface of $g-C_{3} \mathrm{~N}_{4}$. Hydroxyl functional groups may be potential candidates in improving the hydrophilicity of $\mathrm{C}_{3} \mathrm{~N}_{4}$ [3]. Our group had reported on the surface modification of $\mathrm{C}_{3} \mathrm{~N}_{4}$ with hydroxyls using hydrogen peroxide $\left(\mathrm{H}_{2} \mathrm{O}_{2}\right)$, and found that the photocatalytic activity of $\mathrm{C}_{3} \mathrm{~N}_{4}$ was promoted [4]. Additionally, as reported by Li et al., that the photocatalytic activity of $\mathrm{C}_{3} \mathrm{~N}_{4}$ treated in an ammonia solution was improved due to the hydroxyl surface modification [5]. Motivated by this work, we herein developed a hydrothermal method to modify $\mathrm{C}_{3} \mathrm{~N}_{4}$ by the addition of hydroxyls onto the surface. The $\mathrm{pH}$ of the hydrothermal treatment solution was explored, and the insight into the photocatalytic activity improvement was performed and discussed in this work.

\section{Results and Discussions}

The morphology of the as-prepared samples was investigated through TEM. As shown in the TEM image of $\mathrm{C}_{3} \mathrm{~N}_{4}$ (Figure 1a), a layered structure was observed. Due to the ultrathin structure, the edge of the prepared $\mathrm{C}_{3} \mathrm{~N}_{4}$ is partially curly, which is intended to decrease the surface tension. This is typical of the construction of exfoliated carbon scrolls by peeling graphite [6]. After hydrothermal treatment, the morphology as shown in Figure $1 \mathrm{~b}$ was negligibly influenced. The crystal structure of pure $\mathrm{C}_{3} \mathrm{~N}_{4}$ as shown in Figure $1 \mathrm{c}$, two obvious peaks can be observed at the $2 \theta$ of $13.0^{\circ}$ and $27.5^{\circ}$, 
which agree well with the hexagonal phase of graphitic $\mathrm{C}_{3} \mathrm{~N}_{4}$ (JCPDS 87-1526) [2]. With hydroxyl group modifications, as shown in Figure $1 c$, the crystal structure of $\mathrm{C}_{3} \mathrm{~N}_{4}$ was negligibly influenced, indicating that the hydrothermal treatment may not influence the crystal structure of $\mathrm{C}_{3} \mathrm{~N}_{4}$. The $\mathrm{O} 1 \mathrm{~s}$ high-resolution spectra in Figure $1 \mathrm{~d}$ can be fitted with a single peak located at $529.44 \mathrm{eV}$ for $\mathrm{g}-\mathrm{C}_{3} \mathrm{~N}_{4}$, corresponding to the $\mathrm{O}-\mathrm{H}$ bond. After hydrothermal treatment, the peak was negatively shifted by $0.66 \mathrm{eV}$, which may have resulted from the hydroxyl group being bonded with $\mathrm{g}-\mathrm{C}_{3} \mathrm{~N}_{4}$. The optical properties of the as-prepared samples were investigated using DRS, as plotted in Figure 1e, and a rapid increase of the intensity was found with a decrease in the wavelength of the incident to $490 \mathrm{~nm}$. This may be due to the band transition. To evaluate the band gap energy for each sample, the classical Tauc equation was used as plotted in Figure $1 \mathrm{f}$. It was found that the band gap for $\mathrm{C}_{3} \mathrm{~N}_{4}$, as well as for hydroxyl-modified $\mathrm{C}_{3} \mathrm{~N}_{4}$, was approximately equivalent to $2.54 \mathrm{eV}$. This confirms that there are no doped impurity energy levels within the band gap after the hydroxyl surface modification.

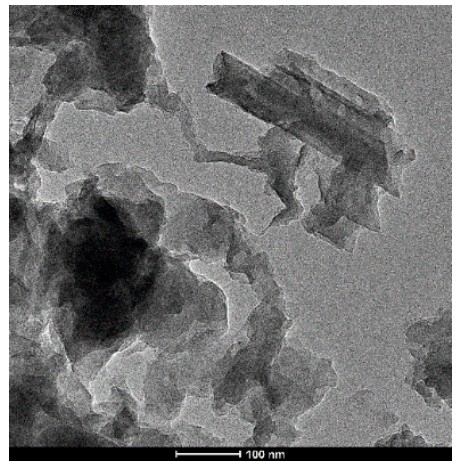

(a)

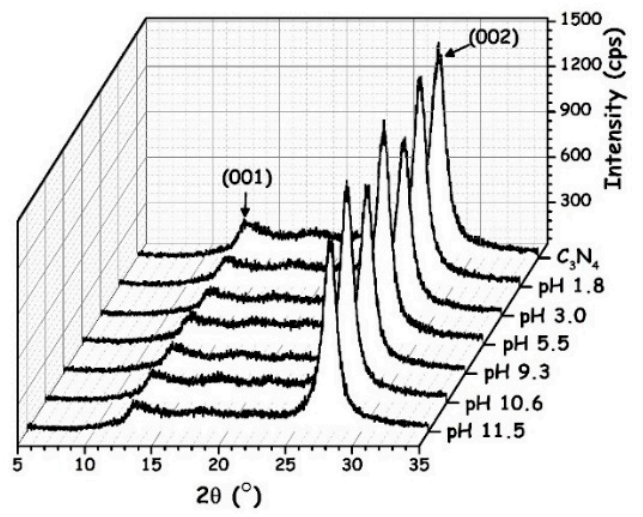

(c)

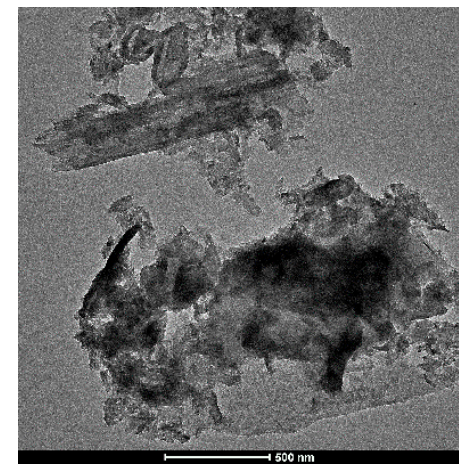

(b)

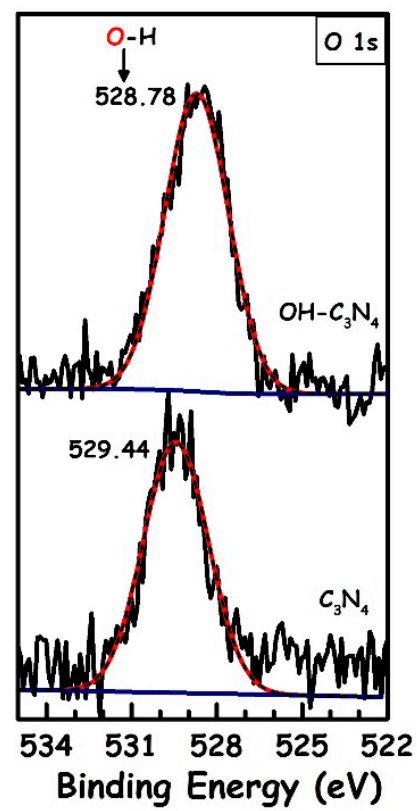

(d)

Figure 1. Cont. 


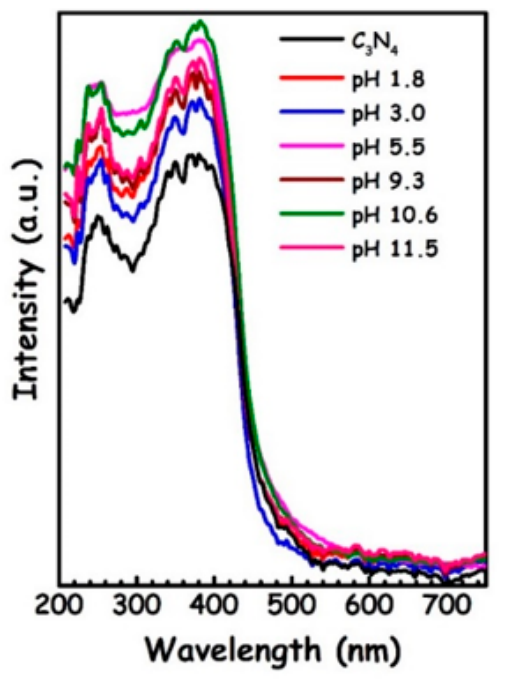

(e)

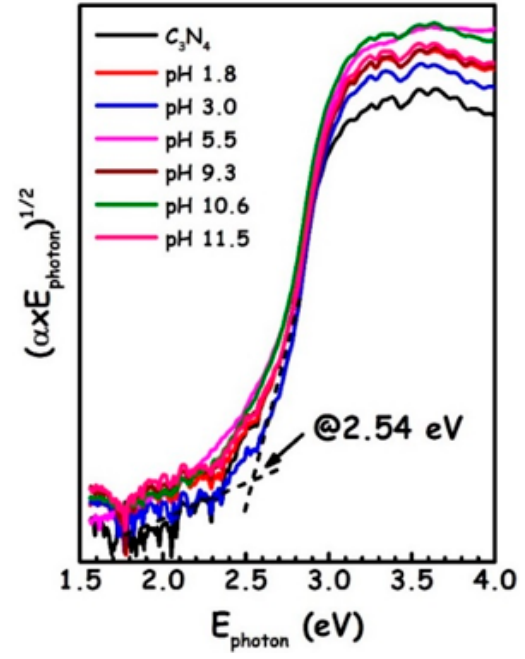

(f)

Figure 1. (a) TEM image of $\mathrm{C}_{3} \mathrm{~N}_{4}$, (b) TEM image of $\mathrm{C}_{3} \mathrm{~N}_{4}$ treated with a precursor solution with $\mathrm{pH}$ 5.5 , (c) XRD patterns, (d) XPS scan for O 1s orbit, (e) DRS, and (f) $\left(\alpha \times E_{\text {photon }}\right)^{1 / 2}$ - $E_{\text {photon }}$ curves for the as-prepared samples.

To further explore the composition of the hydroxyl-modified $\mathrm{C}_{3} \mathrm{~N}_{4}$, FT-IR spectra were used, and plotted in Figure 2a. The peak located at $810 \mathrm{~cm}^{-1}$ was assigned to the typical breathing mode of a s-triazine ring, and the peak located at $890 \mathrm{~cm}^{-1}$ may be due to the out-of-plane bending mode of N-H. A bunch of peaks located at the range of $1200-1700 \mathrm{~cm}^{-1}$ were ascribed to the stretching vibration modes of $\mathrm{C}-\mathrm{N}$ and $\mathrm{C}=\mathrm{N}$ heterocycles. The broad peak at $3000-3250 \mathrm{~cm}^{-1}$ may have resulted from the $\mathrm{N}-\mathrm{H}$ stretching vibration of uncondensed amine and hydroxyl groups [7]. It can be found that the intensity of this peak increased when the $\mathrm{pH}$ of the solution increased. This phenomenon may be due to more hydroxyl groups being adsorbed on the surface of $\mathrm{C}_{3} \mathrm{~N}_{4}$ in a solution with a higher $\mathrm{pH}$; and the amine groups being possibly dissolved in a solution with a lower $\mathrm{pH}$ during the hydrothermal treatment, resulting in the reduction of the intensity of this peak. This is also confirmed by the fact that hydrothermal treatment in a solution with a high $\mathrm{pH}$ favors the addition of more hydroxyls onto $\mathrm{C}_{3} \mathrm{~N}_{4}$. Zeta potentials for the as-prepared samples (Figure $2 \mathrm{~b}$ ) were negatively shifted with an increase in the $\mathrm{pH}$ of the solution in the hydrothermal treatment. This suggests that the zeta potentials became more negative as the amount of hydroxyl groups increased. The more negatively charged surface of the catalyst favors the adsorption of organic pollutants in water, which improves the photocatalytic activity.
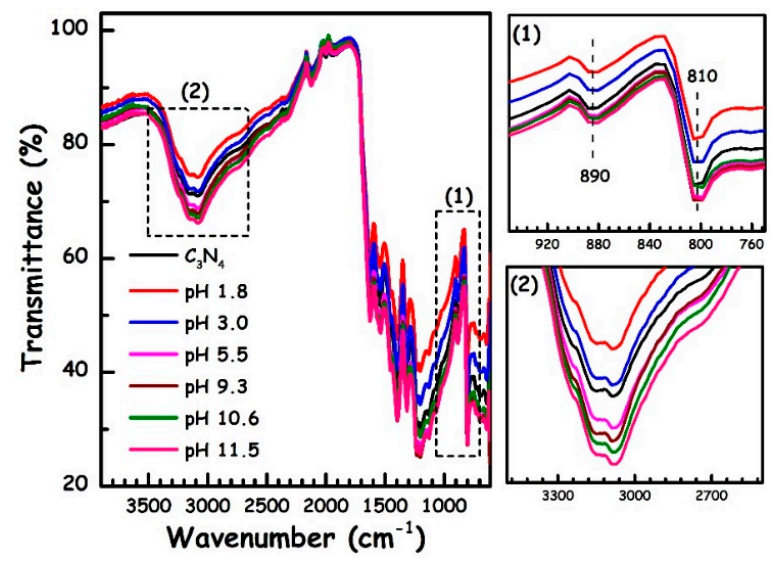

(a)

Figure 2. Cont. 


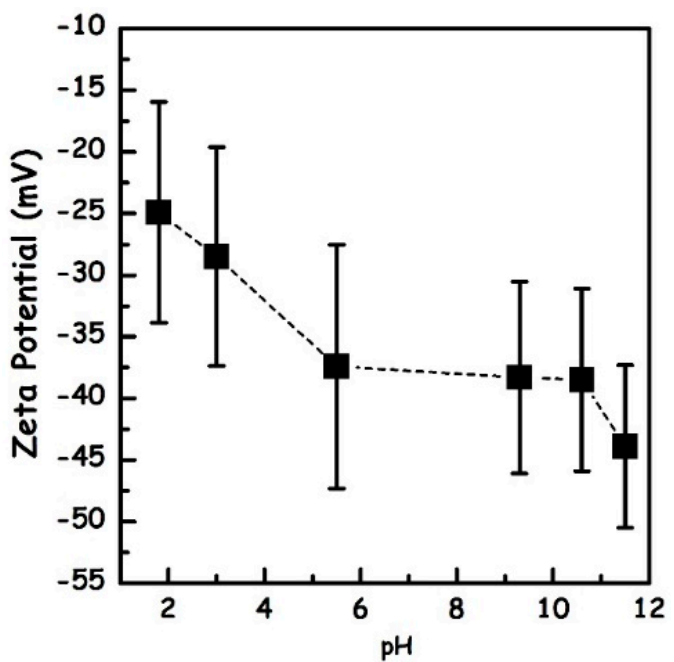

(b)

Figure 2. FT-IR spectra (full spectra and enlarged spectra), and zeta potentials for the as-prepared samples.

To further determine the mechanism of the hydroxyl modifications, DFT simulation was conducted, and the results were shown in Table 1 . To determine the site on hydroxyl-bonded $\mathrm{C}_{3} \mathrm{~N}_{4}$, the free energies of the crystals were calculated. It was found that the free energy of the crystal with $\mathrm{OH}$ that was bonded to the carbon of $\mathrm{C}_{3} \mathrm{~N}_{4}(\mathrm{OH}-\mathrm{C})$ was lower than that of the crystal with $\mathrm{OH}$ that was bonded to the nitrogen of $\mathrm{C}_{3} \mathrm{~N}_{4}(\mathrm{OH}-\mathrm{N})$. This suggests that the crystal may be more stable when the $\mathrm{OH}$ was bonded with the carbon of $\mathrm{C}_{3} \mathrm{~N}_{4}$. The distance between $\mathrm{H}_{2} \mathrm{O}$ and the site on $\mathrm{C}_{3} \mathrm{~N}_{4}$ was also measured, and it was found that the distance was shortened when the $\mathrm{C}_{3} \mathrm{~N}_{4}$ was modified with $-\mathrm{OH}$. The adsorption energy of $\mathrm{H}_{2} \mathrm{O}$ also increased with the modification of $-\mathrm{OH}$ onto $\mathrm{C}_{3} \mathrm{~N}_{4}$. This suggests that the hydroxyl modification may be very promising in the improvement of the photocatalytic activity of $\mathrm{C}_{3} \mathrm{~N}_{4}$ by enhancing the adsorption between the $\mathrm{H}_{2} \mathrm{O}$ /organic and the photocatalyst surface. To further confirm this verdict, the photocatalytic activity of the as-prepared samples was evaluated in the decomposition of phenol under visible light, the results of which were shown in Figure 3. It was found that with hydroxyl modification, both the conversion of phenol and the TOC (total organic carbon) in the solution was enhanced. In addition, the improvement also increased with an increase in the number of hydroxyls on the surface. This provides solid evidence that hydroxyl modification was very effective in enhancing the photocatalytic activity of $\mathrm{C}_{3} \mathrm{~N}_{4}$ through the improvement of the adsorption capacity. 
Table 1. Properties of hydroxyl-modified $\mathrm{C}_{3} \mathrm{~N}_{4}$ and water adsorbed on the surface of $\mathrm{C}_{3} \mathrm{~N}_{4}$ with/without hydroxyl modification. ( $\mathrm{d}$ is the distance between the atom in $\mathrm{H}_{2} \mathrm{O}$ and the adsorption site on $\mathrm{C}_{3} \mathrm{~N}_{4}$ ).

\begin{tabular}{ccccc}
\hline Composition & $\begin{array}{c}\text { Charge Density } \\
\text { Distribution }\end{array}$ & Free Energy $(\mathrm{eV})$ & $d(\AA)$ & $E_{\text {ads }}(\mathrm{eV})$ \\
\hline $\mathrm{OH}-\mathrm{C}$ & -235.01 & 2.025 & -0.67 \\
$\mathrm{OH}-\mathrm{N}$ & & & & \\
& & & & \\
\end{tabular}

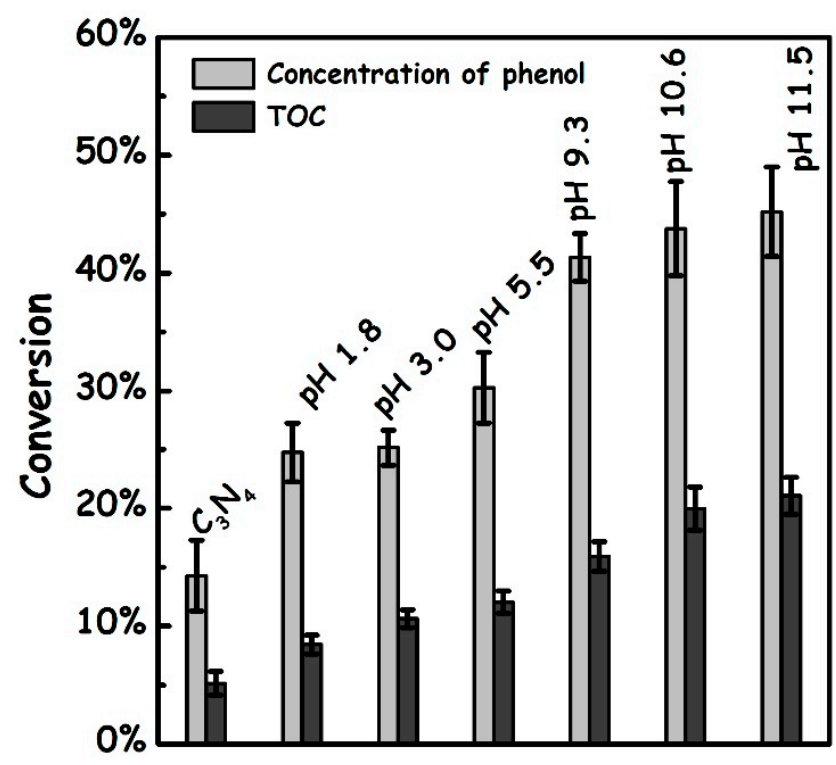

Figure 3. Photocatalytic conversion of phenol in the presence of $g-C_{3} N_{4}$ and modified $g-C_{3} N_{4}$ under visible light for $3 \mathrm{~h}$. ( $\mathrm{pH}$ in this figure represents the $\mathrm{pH}$ of the solution in the hydrothermal surface modification, each data point and error bar represents the mean and the standard errors, respectively, of independent triplicates).

\section{Experimental}

All chemicals were purchased from Fisher Scientific (Canada) unless otherwise mentioned, and used as received. $\mathrm{C}_{3} \mathrm{~N}_{4}$ was prepared by directly heating melamine in a semi-closed system to prevent the sublimation of melamine [8]. Typically, $10 \mathrm{~g}$ of melamine powder, in a crucible with a cover, was heated up to $550{ }^{\circ} \mathrm{C}$ in a muffle furnace with a heating rate of $2.5^{\circ} \mathrm{C} / \mathrm{min}$, and the further deamination treatment was performed for $4 \mathrm{~h}$. After the crucible was naturally cooled down to room temperature, the yellowish powder was mounted and collected for further use. The surface modification of $\mathrm{C}_{3} \mathrm{~N}_{4}$ with hydroxyls was conducted by hydrothermal treatment. Typically, $0.3 \mathrm{~g}$ of $\mathrm{C}_{3} \mathrm{~N}_{4}$ was first dispersed into a $35 \mathrm{~mL}$ solution under ultrasonication for $30 \mathrm{~min}$. Then, the suspension 
was transferred to a $50 \mathrm{~mL}$ Teflon-lined autoclave, which was heated up to $160^{\circ} \mathrm{C}$ for $4 \mathrm{~h}$. The autoclave was then allowed to naturally cool down to room temperature, and the precipitates in the suspension were separated out through centrifugation, and washed with deionized distilled water, several times. To explore the effect of the $\mathrm{pH}$ of the solution in the hydrothermal treatment, it was adjusted using $\mathrm{NaOH}(1 \mathrm{~mol} / \mathrm{L})$ and $\mathrm{HNO}_{3}(1 \mathrm{~mol} / \mathrm{L})$.

Morphology of the as-prepared $\mathrm{C}_{3} \mathrm{~N}_{4}$ was investigated by a transmission electron microscope (TEM, JEM-2100F). Crystal structures of the as-prepared samples were explored using an X-ray powder diffraction instrument (Bruker-AXS, Karlsruhe, Germany). An ultraviolet-visible light diffuse reflectance spectrophotometer (DRS) was employed to determine the optical properties of the as-prepared samples. Fourier transform infrared spectroscopy (FTIR) was also done at room temperature with a Cary 630 (Agilent Technologies). Zeta potentials of hydroxyl-modified $\mathrm{C}_{3} \mathrm{~N}_{4}$ were tested using a Zetasizer (Malvern Panalytical). DFT simulations were performed using the Vienna ab initio simulation package (VASP) $[9,10]$. The ion-electron interaction is described with the projector augmented wave (PAW) method [11]. The electron exchange-correlation is represented by the Perdew, Burke, and Ernzerhof (PBE) function of the generalized gradient approximation (GGA) [12]. A cut-off energy of $450 \mathrm{eV}$ was used for the plane-wave basis set. The calculations were done on periodical supercells of the $\mathrm{C}_{3} \mathrm{~N}_{4}$ monolayer with a $3 \times 3 \times 1$ Monkhorst Pack k-point sampling. The charge density distribution and the distance between bonds were analyzed using VESTA [13].

The photocatalytic activity of as-prepared samples was evaluated with regard to the degradation of phenol under visible light irradiation. The light source was provided by a 300-W halogen tungsten projector lamp (Ushio) equipped with a UV cut-off (Kenko Zeta, transmittance $>90 \%$ ) to filter out wavelength below $400 \mathrm{~nm}$. Typically, in each test, $0.10 \mathrm{~g}$ of photocatalyst was added into a $100 \mathrm{~mL}$ of phenol solution with an initial concentration of $10 \mathrm{mg}$ (phenol)/L ( $\mathrm{pH} 4.5)$. The mixture was magnetically stirred in the dark for $1 \mathrm{~h}$ to reach an adsorption/desorption equilibrium prior to the photocatalysis experiment. After $3 \mathrm{~h}, 1 \mathrm{~mL}$ aliquots were drawn and centrifuged. The supernatant was analyzed using a high-performance liquid chromatograph (HPLC, Agilent 1100 series) equipped with a UV-Vis detector. The total organic carbon (TOC) was evaluated on an Appollo 9000 TOC analyzer equipped with a non-dispersive Infra-Red (NDIR) detector. The combustion temperature was fixed at $750{ }^{\circ} \mathrm{C}$. To explore the repeatability of the activity test, the photocatalytic activity for each sample was repeated for three times.

\section{Conclusions}

Hydrothermal treatment may be an effective approach in the modification of the surface of $g-\mathrm{C}_{3} \mathrm{~N}_{4}$ via the addition of hydroxyl functional groups. The primary function of hydroxyls on the surface is to increase the adsorption rate of water, as well as that of organics in water. This improvement may directly improve the photocatalytic activity. This work provides an effective method to modify the surface with hydroxyls, which can be extended to other applications, such as for other semiconductors with a hydrophobic surface and in membrane science.

Author Contributions: Z.L. and X.M. conceived and designed the experiments; Z.L. performed the experiments; Z.L. and X.M. analyzed the data; Z.Z. contributed reagents/materials/analysis tools; Z.L. wrote the paper.

Funding: This research was funded by Natural Sciences and Engineering Research Council of Canada (NSERC).

Acknowledgments: This work was financially supported by a discovery grant from the Natural Sciences and Engineering Research Council of Canada (NSERC). Zizhen Li and Xiangchao Meng are the recipients of scholarships from the China Scholarship Council (CSC) for the duration of this work. The authors acknowledge Anthony Ivanenko for his help with English correction of this manuscript.

Conflicts of Interest: The authors declare no conflict of interest. 


\section{References}

1. Ong, W.J.; Tan, L.L.; Ng, Y.H.; Yong, S.T.; Chai, S.P. Graphitic carbon nitride $\left(\mathrm{g}-\mathrm{C}_{3} \mathrm{~N}_{4}\right)$-based photocatalysts for artificial photosynthesis and environmental remediation: Are we a step closer to achieving sustainability? Chem. Rev. 2016, 116, 7159-7329. [CrossRef] [PubMed]

2. Wang, X.; Maeda, K.; Thomas, A.; Takanabe, K.; Xin, G.; Carlsson, J.M.; Domen, K.; Antonietti, M. A metal-free polymeric photocatalyst for hydrogen production from water under visible light. Nat. Mater. 2008, 8, 76. [CrossRef] [PubMed]

3. Kim, W.J.; Kim, S.; Lee, B.S.; Kim, A.; Ah, C.S.; Huh, C.; Sung, G.Y.; Yun, W.S. Enhanced protein immobilization efficiency on $\mathrm{TiO}_{2}$ surface modified with a hydroxyl functional group. Langmuir 2009, 25, 11692-11697. [CrossRef] [PubMed]

4. Zheng, Y.; Zhang, Z.; Li, C.; Proulx, S. Surface hydroxylation of graphitic carbon nitride: Enhanced visible light photocatalytic activity. Mater. Res. Bull. 2016, 84, 46-56. [CrossRef]

5. Li, F.T.; Zhao, Y.; Wang, Q.; Wang, X.J.; Hao, Y.J.; Liu, R.H.; Zhao, D. Enhanced visible-light photocatalytic activity of active $\mathrm{Al}_{2} \mathrm{O}_{3} / \mathrm{g}-\mathrm{C}_{3} \mathrm{~N}_{4}$ heterojunctions synthesized via surface hydroxyl modification. J. Hazard. Mater. 2015, 283, 371-381. [CrossRef] [PubMed]

6. Lin, Z.; Wang, X. Nanostructure Engineering and Doping of Conjugated Carbon Nitride Semiconductors for Hydrogen Photosynthesis. Angew. Chem. Ger. Ed. 2013, 125, 1779. [CrossRef]

7. Huang, Y.; Wang, Y.; Bi, Y.; Jin, J.; Ehsan, M.F.; Fu, M.; He, T. Preparation of 2D hydroxyl-rich carbon nitride nanosheets for photocatalytic reduction of $\mathrm{CO}_{2}$. RSC Adv. 2015, 5, 33254. [CrossRef]

8. Yan, S.C.; Li, Z.S.; Zou, Z.G. Photodegradation performance of $\mathrm{g}-\mathrm{C}_{3} \mathrm{~N}_{4}$ fabricated by directly heating melamine. Langmuir 2009, 25, 10397. [CrossRef] [PubMed]

9. Kresse, G.; Hafner, J. Ab initio molecular dynamics for liquid metals. Phys. Rev. B 1993, 47, 558. [CrossRef]

10. Kresse, G.; Furthmüller, J. Efficient iterative schemes for ab initio total-energy calculations using a plane-wave basis set. Phys. Rev. B 1996, 54, 11169. [CrossRef]

11. Blöchl, P.E. Projector augmented-wave method. Phys. Rev. B 1994, 50, 17953. [CrossRef]

12. Perdew, J.P.; Burke, K.; Ernzerhof, M. Generalized Gradient Approximation Made Simple. Phys. Rev. Lett. 1996, 77, 3865. [CrossRef] [PubMed]

13. Momma, K.; Izumi, F. VESTA 3 for three-dimensional visualization of crystal, volumetric and morphology data. J. Appl. Crystallogr. 2011, 44, 1272-1276. [CrossRef] 